\title{
Detection of maternal-fetal microchimerism in the inflammatory lesions of patients with Siögren's syndrome
}

\author{
M Kuroki, A Okayama, S Nakamura, T Sasaki, K Murai, R Shiba, M Shinohara, \\ H Tsubouchi
}

Ann Rheum Dis 2002;61:1041-1046

See end of article for authors' affiliations

Correspondence to: Dr A Okayama,

Department of Internal Medicine II, Miyazaki Medical College, 5200

Kihara, Kiyotake, Miyazaki 889-1601, Japan; okayama@

post1.miyazaki-med.ac.jp

Accepted 9 April 2002

\begin{abstract}
Background: A possible relation between maternal-fetal microchimerism and autoimmune diseases with some similarities to chronic graft versus host disease (cGVHD) has been reported.

Objective: To investigate whether cells with male DNA exist in female patients with Sjögren's syndrome (SS) as SS has clinical features similar to those of cGVHD.

Methods: DNA was extracted from 27 samples of peripheral blood mononuclear cells (PBMC), 42 biopsy samples of labial salivary glands (LSG), and nine samples of bronchoalveolar lavage fluid (BALF) cells from 56 female patients with SS. The presence of male DNA was determined by nested polymerase chain reaction (PCR) and by fluorescence in situ hybridisation (FISH).

Results: Among 56 female patients with SS, 42 patients had at least one male child. Among those 42 patients, none of the 22 PBMC but 10/28 (36\%) LSG samples tested positive by PCR for the $Y$ chromosome-specific sequence $(p=0.0013)$. The $Y$ chromosome-specific sequence was not detected in the samples of LSG in 10 patients without SS. In the BALF samples 2/9 (22\%) patients with SS tested positive by PCR. Cells containing the $\mathrm{Y}$ chromosome were shown to exist in all the LSG specimens from three female patients with SS by FISH.

Conclusions: Maternal-fetal microchimerism was shown for the first time to exist in the salivary glands and lungs of female patients with SS in this study. The presence of non-host cells in the inflammatory lesions but not in the peripheral blood suggests a possible role for maternal-fetal microchimerism in the pathogenesis of SS.
\end{abstract}

F etal cells persist in a woman's circulation for years after pregnancy and have been detected in the peripheral blood of women up to 27 years post partum. ${ }^{1}$ Nelson et al investigated the relation between maternal-fetal microchimerism and autoimmune disease and reported that a higher concentration of male DNA in the peripheral blood was detected in patients with systemic sclerosis (SSc) than in healthy women. ${ }^{2}$ Cells with male DNA, which were probably derived from fetal cells, were also found in the skin lesions of female patients with SSc and of pregnant women with polymorphic eruptions. ${ }^{34}$ Moreover, chimeric cells derived from mothers were detectable in the peripheral blood and inflammatory lesions of patients with juvenile idiopathic inflammatory myopathy and juvenile dermatomyositis. ${ }^{56}$ These findings suggest that maternal-fetal microchimerism may be involved in the pathogenesis of these diseases. The possibility that maternal-fetal microchimerism plays a part in other autoimmune diseases has been suggested "; however, contradictory results showing a lack of association between microchimerism and autoimmune disease have also been

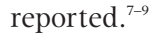

Sjögren's syndrome (SS) is characterised by chronic inflammatory lesions, mainly affecting the excretion glands. Various factors such as genetic background, autoimmunity, and viral infections are possible causes of this disease. ${ }^{10}$ However, the exact mechanism and crucial factors for developing SS are still unknown. The histology of SS is similar to that of the lesions of chronic graft versus host disease (cGVHD) after allogeneic bone marrow transplantation. ${ }^{11-13}$ In this study we examined the presence of a Y chromosome-specific sequence in the peripheral blood as well as in inflammatory lesions such as labial glands, and the interstitial pneumonia of patients with SS, in an attempt to determine whether microchimerism played a part in the pathogenesis of SS.

\section{PATIENTS AND METHODS \\ Subjects}

Fifty six female patients with SS, who were admitted to Miyazaki Medical College Hospital or Kyushu University Dental Hospital and whose samples are described below, were included in this study (table 1). The mean age of the patients with SS was 51.7 years (range 17-74). The diagnosis of SS was established according to the diagnostic criteria for definite SS proposed by the Research Committee on Sjögren's syndrome of the Ministry of Health and Welfare of the Japanese government. ${ }^{14}$ Twenty of 56 patients had associated collagen diseases (six had rheumatoid arthritis, four had systemic lupus erythematosus, three had SSc, two had limited cutaneous sclerosis, five had mixed connective tissue disease, one had polymyositis).

Peripheral blood mononuclear cells (PBMC) were obtained from 27 patients by Ficoll-Hypaque density gradient centrifugation. Biopsy specimens of labial salivary glands (LSG) taken in the course of the normal procedure for disease diagnosis were also available from 42 patients with SS. Nine patients with SS had interstitial pulmonary lesions, and bronchoscopic examinations were performed. The pelleted cells from the bronchoalveolar lavage fluid (BALF) were also available from these patients. PBMC from eight healthy female volunteers who did not have a history of pregnancy were also tested. For controls, we used LSG specimens from 10 female patients with

Abbreviations: BALF, bronchoalveolar lavage fluid; $C G V H D$, chronic graft versus host disease; FISH, fluorescence in situ hybridisation; LSG, labial salivary glands; PBMC, peripheral blood mononuclear cells; PCR, polymerase chain reaction; SRY, sex determining region Y chromosome; SS, Sjögren's syndrome; SSc, systemic sclerosis; SSC, saline sodium citrate 
Table 1 Detection of the $Y$ chromosome-specific sequence in patients with Siögren's syndrome by polymerase chain reaction

\begin{tabular}{|c|c|c|c|c|c|c|c|}
\hline \multirow[b]{2}{*}{ Patient No } & \multirow[b]{2}{*}{ Age (years) } & \multicolumn{3}{|c|}{ Samples } & \multirow[b]{2}{*}{ Number of sons } & \multirow[b]{2}{*}{ Abortion } & \multirow[b]{2}{*}{ Blood transfusion } \\
\hline & & PBMC & LSG & BALF & & & \\
\hline 1 & 67 & - & - & NT & 1 & + & + \\
\hline 2 & 58 & - & - & NT & 2 & + & - \\
\hline 3 & 39 & - & - & NT & 1 & - & - \\
\hline 4 & 53 & - & - & NT & 2 & - & - \\
\hline 5 & 43 & - & - & NT & 1 & - & - \\
\hline 6 & 37 & - & + & NT & 1 & - & - \\
\hline 7 & 55 & - & - & NT & 1 & - & - \\
\hline 8 & 65 & - & - & - & 2 & - & - \\
\hline 9 & 58 & - & - & - & 1 & - & + \\
\hline 10 & 49 & - & NT & - & 1 & - & - \\
\hline 11 & 58 & - & NT & - & 1 & - & - \\
\hline 12 & 44 & - & NT & + & 4 & + & - \\
\hline 13 & 58 & - & NT & + & 1 & - & - \\
\hline 14 & 59 & - & NT & - & 2 & - & - \\
\hline 15 & 68 & - & NT & - & 2 & - & - \\
\hline 16 & 57 & - & NT & NT & 3 & - & - \\
\hline 17 & 54 & - & NT & NT & 1 & - & - \\
\hline 18 & 47 & - & NT & NT & 1 & - & - \\
\hline 19 & 64 & - & NT & NT & 3 & - & - \\
\hline 20 & 41 & - & NT & NT & 2 & - & - \\
\hline 21 & 43 & - & NT & NT & 2 & - & - \\
\hline 22 & 40 & - & NT & NT & 1 & - & - \\
\hline 23 & 69 & NT & + & NT & 2 & + & - \\
\hline 24 & 43 & NT & - & NT & 1 & + & - \\
\hline 25 & 53 & NT & - & NT & 2 & - & - \\
\hline 26 & 62 & NT & + & NT & 1 & - & - \\
\hline 27 & 59 & NT & - & NT & 2 & - & - \\
\hline 28 & 61 & NT & - & NT & 1 & - & - \\
\hline 29 & 51 & NT & - & NT & 1 & - & - \\
\hline 30 & 72 & NT & + & NT & 2 & - & - \\
\hline 31 & 66 & NT & - & NT & 2 & - & - \\
\hline 32 & 45 & NT & + & NT & 1 & - & - \\
\hline 33 & 56 & NT & - & NT & 1 & - & - \\
\hline 34 & 72 & NT & - & NT & 1 & - & - \\
\hline 35 & 50 & NT & + & NT & 2 & - & - \\
\hline 36 & 63 & NT & - & NT & 1 & - & - \\
\hline 37 & 28 & NT & + & NT & 2 & - & - \\
\hline 38 & 71 & NT & + & NT & 2 & - & - \\
\hline 39 & 48 & NT & NT & - & 1 & - & - \\
\hline 40 & 49 & NT & + & NT & 1 & - & - \\
\hline 41 & 49 & NT & + & NT & 1 & - & - \\
\hline 42 & 51 & NT & - & NT & 1 & - & - \\
\hline 43 & 66 & - & - & NT & 0 & + & - \\
\hline 44 & 64 & - & - & NT & 0 & + & - \\
\hline 45 & 51 & - & - & NT & 0 & - & - \\
\hline 46 & 24 & - & - & NT & 0 & - & - \\
\hline 47 & 34 & + & + & NT & 0 & - & + \\
\hline 48 & 71 & NT & - & NT & 0 & + & - \\
\hline 49 & 33 & NT & + & NT & 0 & + & - \\
\hline 50 & 59 & NT & - & NT & 0 & - & + \\
\hline 51 & 22 & NT & - & NT & 0 & - & - \\
\hline 52 & 74 & NT & - & NT & 0 & - & - \\
\hline 53 & 62 & NT & - & NT & 0 & - & - \\
\hline 54 & 17 & NT & - & NT & 0 & - & - \\
\hline 55 & 25 & NT & - & NT & 0 & - & - \\
\hline 56 & 67 & NT & - & NT & 0 & - & - \\
\hline
\end{tabular}

mucocele, who had no clinical or laboratory evidence of systemic autoimmune diseases, and pelleted cells from the BALF of 15 female patients with other lung diseases (eight with pulmonary infection, three with lung cancer, two with rheumatoid arthritis, and two with sarcoidosis). Each patient in the control group had at least one male child. All samples were stored at $-80^{\circ} \mathrm{C}$ before use. Informed consent was obtained from the study participants.

\section{Detection of the $\mathrm{Y}$ chromosome-specific sequence by} nested polymerase chain reaction (PCR)

Genomic DNA was isolated from PBMC, biopsy specimens of LSG, and pelleted cells of BALF by sodium dodecyl sulphateprotease $\mathrm{K}$ digestion at $56^{\circ} \mathrm{C}$, followed by phenol-chloroform extraction and ethanol precipitation. The DNA samples were used as templates for the nested PCR to amplify the specific Y chromosome sequence. Each $100 \mu \mathrm{l}$ of the reaction mixture contained $1 \mu \mathrm{g}$ of sample DNA, $3 \mathrm{U}$ Taq DNA polymerase (TaKaRa, Tokyo, Japan), $250 \mu \mathrm{mol} / \mathrm{l}$ of each deoxynucleotide triphosphate (dATP, dCTP, dGTP, and dTTP), $0.5 \mu \mathrm{mol} / \mathrm{l}$ of each primer described below, $50 \mathrm{mmol} / \mathrm{l} \mathrm{KCl}, 10 \mathrm{mmol} / \mathrm{l}$ Tris- $\mathrm{HCl}$ ( $\mathrm{pH} 8.0$ ), and $1.0 \mathrm{mmol} / \mathrm{l} \mathrm{MgCl}_{2}$. The first amplification was done with primers APl (5'-GAATATTCCCGCTCTCCGGA-3') and AP2 (5'-ACAACCTGTTGTCCAGTTGC- $\left.3^{\prime}\right)$, and the second amplification was done with primers SRYIF (5'CAGTGTGAAACGGGAGAAAACAGT-3') and SRY2R (5'CTTCCGACGAGGTCGATACTTATA-3'), which amplify the sex determining region $\mathrm{Y}$ chromosome (SRY). ${ }^{15} 16$ Fifty three 


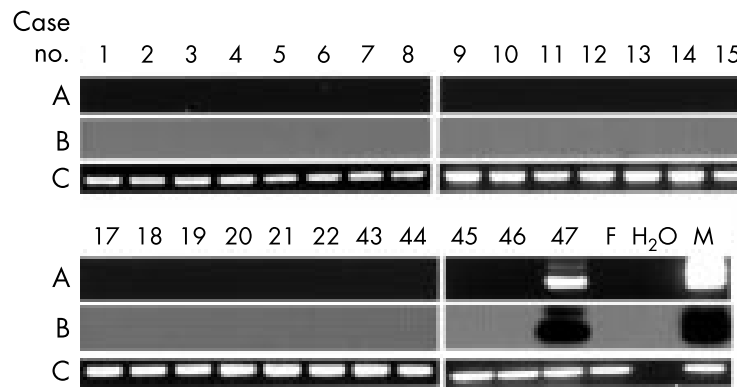

Figure 1 Detection of the $Y$ chromosome-specific sequence in peripheral blood mononuclear cells from patients with SS with ethidium bromide staining (A) and its Southern blot analysis (B). Detection of $\beta$-globin DNA by PCR with ethidium bromide staining is also shown as an internal control (C). Lane $\mathrm{H}_{2} \mathrm{O}$, no DNA; lane $\mathrm{F}$, female DNA control; lane $\mathrm{M}$, male DNA control.

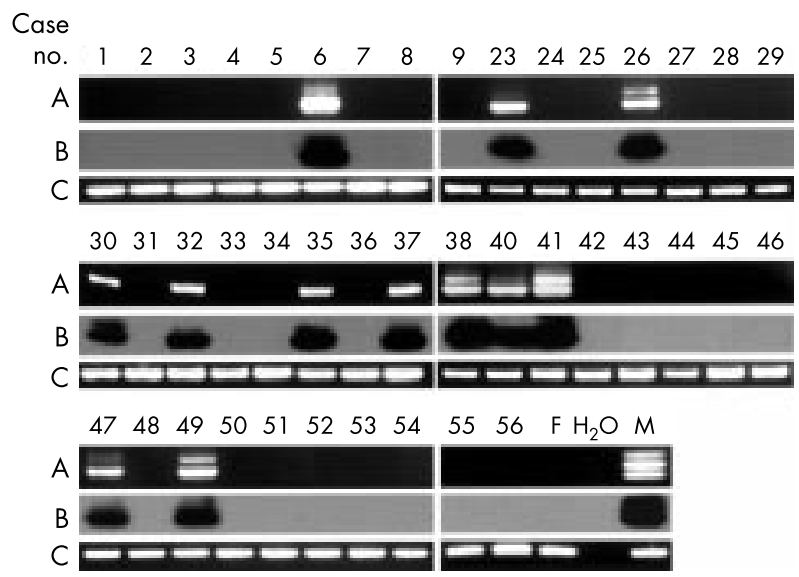

Figure 2 Detection of the $Y$ chromosome-specific sequence in the biopsy specimens of the labial salivary glands from patients with SS. Other details are as in fig 1.

amplification cycles were performed in total. The conditions for amplification were 30 cycles of denaturation at $95^{\circ} \mathrm{C}$ (one minute), annealing at $53^{\circ} \mathrm{C}$ (one minute), and extension at $72^{\circ} \mathrm{C}$ (90 seconds), followed by 23 cycles of denaturation at $95^{\circ} \mathrm{C}$ (one minute), annealing at $60^{\circ} \mathrm{C}$ (one minute), and extension at $72^{\circ} \mathrm{C}$ (one minute). All PCR analyses contained two negative controls (without DNA and with DNA from a healthy woman without a history of pregnancy) and one positive control (male DNA). The resulting 270 bp Y chromosomespecific fragment was identified by ethidium bromide staining after electrophoresis on a $2 \%$ agarose gel. The PCR was prepared taking special caution to avoid external contamination. Positive micropipettes were used, and the PCR products were analysed in a different building from that in which the PCR was conducted.

The sensitivity of the nested PCR was examined using genomic DNA from a healthy man that was diluted in that from a healthy woman. The sensitivity of detection was as low as one copy of the target sequence in $1 \mu \mathrm{g}$ DNA (data not shown). The specificity was confirmed by Southern hybridisation. The oligoprobe SRY3FR (5'CTCAGAGATCAGCAAGCAGCTGGGATACCA-3') was labelled using the 3'end labelling kit with streptavidin-AP (NEN Life Science Products, Boston, MA) and used for the hybridisation of the electrophoresis separated PCR products that were transferred to the filter. A chemiluminescence signal was detected using CDP-star nucleic acid chemiluminescence reagent (NEN Life Science Products, Boston, MA). All steps for the procedure followed the manufacturer's instructions. Human $\beta$-globin DNA was amplified using primers KM29/ KM38 (Takara, Tokyo, Japan) as an internal control.

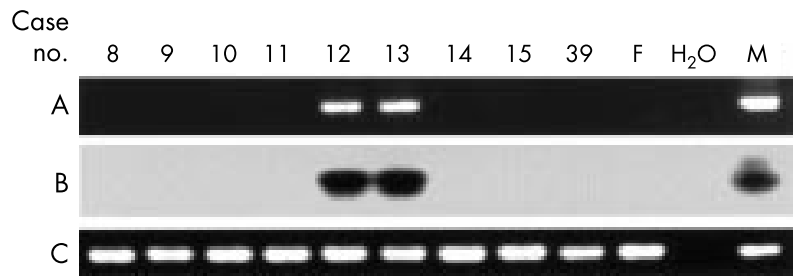

Figure 3 Detection of the $Y$ chromosome-specific sequence in the pelleted cells from the bronchoalveolar lavage fluid from patients with SS. Other details are as in fig 1.

Table 2 Positive rates of the Y-chromosome specific sequence in patients with and without Siögren's syndrome

\begin{tabular}{llll}
\hline & \multicolumn{2}{l}{ Samples } & \\
\cline { 2 - 4 } & PBMC & LSG & BALF \\
\hline SS & $0 / 22$ & $10 / 28(35.7 \%)^{*} \dagger$ & $2 / 9(22.2 \%)$ \\
Without SS & NT & $0 / 10$ & $0 / 15$ \\
\hline
\end{tabular}

*PBMC, peripheral blood mononuclear cells; $†$ LSG, labial salivary gland; BALF, bronchoalveolar lavage fluid; SS, patients with Siögren's syndrome who have at least one male child; Without SS, patients with other diseases not due to Siögren's syndrome; NT, not tested.

${ }^{*} \mathrm{p}=0.0013$, LSG of patients with SS $\vee$ PBMC of patients with SS; $t p=0.028$, LSG of patients with SS $v$ without SS.

\section{Detection of cells containing the $Y$ chromosome in the LSG biopsy specimens by fluorescence in situ hybridisation (FISH)}

The LSG specimens from three patients with SS (Nos 40, 41, and 49), which tested positive for the Y chromosome-specific sequence by PCR, were available for FISH analysis to determine whether cells containing the Y chromosome were detectable. Sections $(5 \mu \mathrm{m})$ of frozen LSG biopsy specimens, which were placed on positively charged glass slides, were treated with 75 $\mathrm{mM} \mathrm{KCl}$ at room temperature for 10 minutes. The samples were then fixed with Carnoy's solution (methanol:acetic acid $=3: 1$ by volume) at room temperature for 10 minutes and dried by air. The sections were treated with RNase A at $37^{\circ} \mathrm{C}$ for $30 \mathrm{~min}$ utes, followed by washing in $2 \times$ saline sodium citrate (SSC) at room temperature for five minutes twice. The sections were treated with $10 \%$ pepsin solution (DAKO, Carpinteria, CA) at $37^{\circ} \mathrm{C}$ for five minutes, washed twice with phosphate buffered saline at room temperature for five minutes, dehydrated through a graded series of alcohols, and allowed to air dry. The slides were washed with $2 \times \mathrm{SSC}$ and $0.1 \% \mathrm{NP}-40$ at $37^{\circ} \mathrm{C}$ for 30 minutes, and dehydrated through a graded series of alcohol. After air drying, the tissues were denatured by treating them with $70 \%$ formamide with $2 \times \mathrm{SSC}(\mathrm{pH} 7.0)$ at $73^{\circ} \mathrm{C}$ for five minutes. The rhodamine labelled $X$ chromosome probe and fluorescein labelled Y chromosome probe (Applied Genetics Laboratories, Melbourne, FL) were used for the hybridisation as recommended by the manufacturer. Each slide was covered with $10 \mu \mathrm{l}$ of the probe solution, cover-slipped, and incubated overnight at $37^{\circ} \mathrm{C}$. The tissue sections were washed in $2 \times \mathrm{SSC}$ with NP-40 three times, then counterstained with $10 \mu \mathrm{l}$ 4',6-diamino-2-phenylindole dihydrochloride (Antifade; Ventana Medical Systems, Tucson, AZ), cover-slipped, and viewed using a Leica microscope (Leica, Wetzlar, Germany). LSG samples from a female patient without SS and from a male patient with SS were used as a negative and a positive control, respectively.

\section{Statistical methods}

We used Fisher's exact probability test to examine the statistical significance between two estimated values of positive rates of the Y chromosome-specific sequence. 

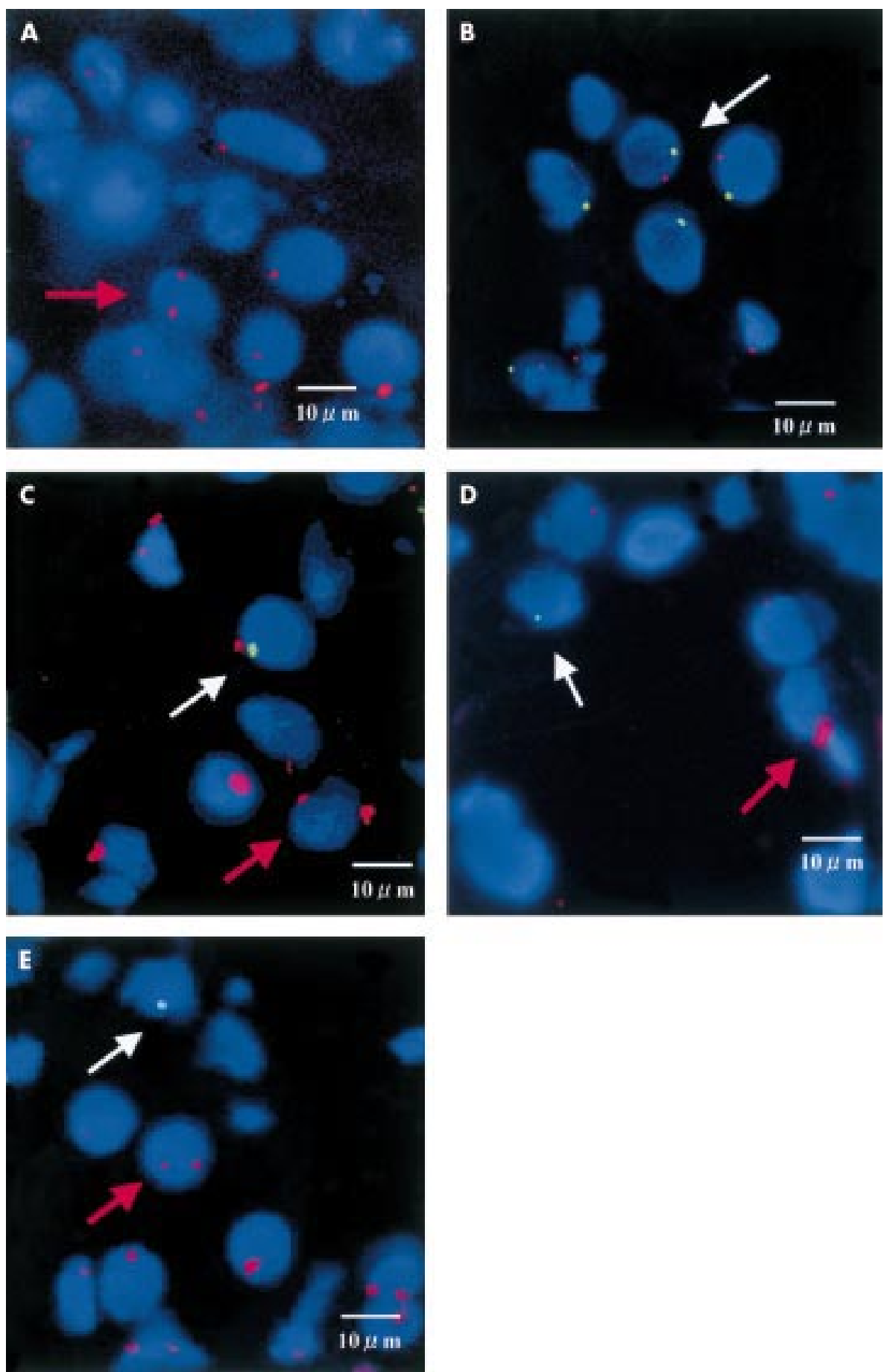

Figure 4 Fluorescence in situ hybridisation to detect the $Y$ chromosome-containing cells in the biopsy specimens of the labial salivary glands. The $Y$ chromosome probe was labelled with fluorescein (green signal), and the $X$ chromosome probe was labelled with rhodamine red (red signal). (A) A female patient without SS (a negative control). Nucleus containing two $X$ chromosomes (red signals). (B) A male patient with SS (a positive control). Nucleus containing one $X$ chromosome (red signal) and one $Y$ chromosome (green signal). (C, D, E) Female patients with SS who tested positive for the Y chromosome-specific sequence by PCR (Nos 40, 41, and 49, respectively) (study subjects). White arrow, nucleus containing one $\mathrm{Y}$ chromosome (green signal); red arrow, nucleus containing two $\mathrm{X}$ chromosomes (red signals).

\section{RESULTS}

Among 56 female patients with SS, 42 patients (Nos 1-42) had at least one male child (table 1). Among those 42 patients, none of the 22 PBMC samples (Nos 1-22) tested positive for the SRY when they were examined by nested PCR ( fig 1, table 1). In contrast, 10 (Nos 6, 23, 26, 30, 32, 35, 37, 38, 40, and 41) of the 28 LSG samples ( $36 \%$ ) tested positive for the SRY ( fig 2, table 1). There was no difference in the incidence of SRY detection in LSG between the patients with primary and secondary SS. One of 10 SRY positive patients also had SSc (No 41 ), but her skin lesion could not be examined in this study. The incidence of the SRY in LSG (10/28) was significantly higher than that in PBMC of the patients with SS and with at least one male child $(0 / 22) \quad(p=0.0013$, Fisher's exact probability test) (table 2). None of the PBMC samples from eight healthy women who did not have any history of 
pregnancy and none of the LSG samples from 10 female patients without SS tested positive. The positive rate of the SRY was significantly higher in the samples of LSG in patients with SS $(10 / 28)$ than in those without SS $(0 / 10)(p=0.028$, Fisher's exact probability test) (table 2 ). In the BALF samples, positive results were found in two (Nos 12 and 13) of nine patients with SS and with at least one male child (22\%) (fig 3, table 1). None of the 15 female patients without SS but with other lung diseases tested positive for the SRY. The specificity of the results of the PCR was confirmed by Southern hybridisation (figs $1-3 \mathrm{~B}$ ). All samples tested positive for $\beta$-globin DNA (figs 1-3C).

Two patients (Nos 47 and 49) tested positive for the SRY even though they did not have a male child (table 1). Patient No 47, who tested positive for the SRY in the samples of both PBMC and LSG, had a history of blood transfusion (figs 1 and 2). Patient No 49, who tested positive for the SRY in the sample of LSG, had a history of abortion (fig 2).

We tested the LSG biopsy specimens for cells containing the Y chromosome by FISH and found none in the LSG specimen from a female patient without SS as a negative control (fig 4A). Nucleated cells containing one X chromosome and one $Y$ chromosome were seen in the LSG specimen from a male patient with SS as a positive control (fig 4B). The LSG specimens from three patients with SS (Nos 40, 41, and 49), which tested positive for SRY by PCR, were available for the detection of the cells containing the Y chromosome by FISH (figs 4C, D, and E, respectively). As many as one to three cells could be detected among the 3000 examined cells in those samples.

\section{DISCUSSION}

Male DNA was shown to exist in the biopsy samples of LSG from a significant number (about 36\%) of female patients with SS and with at least one male child by PCR. External contamination of male DNA in the experiment was unlikely because none of the LSG and BALF samples from female patients without SS and none of the PBMC samples from healthy women who did not have a history of pregnancy tested positive. Moreover, FISH confirmed that the Y chromosome-containing cells were present in all tested samples of LSG tissue from three patients. The patients (Nos 6, $23,26,30,32,35,37,38,40$, and 41) who tested positive for male DNA in LSG and who had at least one male child did not have a history of blood transfusion. Therefore, the cells with male DNA were likely to have been derived from fetal cells, as was previously reported for the cases of SSc. ${ }^{25}$

Some patients (Nos 23, 26, 30, and 38) were more than 60 years old. Fetal cells were reported to be detectable in the peripheral blood of women up to 27 years post partum. ' Possibly, the subjects in this study who were older than 60 had the last male child when they were 30-40 years old, although we do not have exact data about the time of pregnancy. Therefore, we did not find it surprising that the chimeric cells derived from pregnancy could still be detected 20-30 years after the pregnancy.

Male DNA was also shown to exist in the BALF samples from two additional patients (Nos 12 and 13) with interstitial pneumonia, which is also an inflammatory lesion of patients with SS. However, none of the PBMC samples from the patients with SS and with at least one male child tested positive for male DNA. We tried to determine whether any differences in the clinical pictures and the histological grade of SS in LSG existed between SRY positive and SRY negative subjects; however, we did not find such differences, and the presence of SRY was not found to be associated with the presence of particular autoantibodies.

As far as we know, only two previous studies have aimed at detecting microchimerism (cells with male DNA) in female patients with SS, and the targets of both studies were only peripheral blood. Miyashita et al reported that male DNA in PBMC was detectable in $20 \%$ of healthy women and $33 \%$ of female patients with SS. ${ }^{17}$ There was no significant difference between these two groups. The target sequence for the primers they used was DYZl, which is known to exist as multicopies in human eukaryotic cells. ${ }^{18}$ This might be the reason for the higher incidence of female patients with male DNA positive cells in the peripheral blood in their study. Toda et al used PCR to test whether cells with male DNA exist in PBMC or in the CD34+ cell enriched fraction of peripheral blood from patients with SS. ${ }^{9}$ The sensitivity of the detection of their assay was reported as one male cell among $1.67 \times 10^{5}$ female cells, which was a level of sensitivity similar to that in this study. They reported that cells with male DNA were not detected in the peripheral blood of patients with SS, and this result was consistent with ours, with the exception of one patient with a history of blood transfusion. Therefore, the amount of male DNA in the peripheral blood of patients with SS is likely to be very small. In contrast with the results with peripheral blood, cells with male DNA were detectable in the biopsy specimens of LSG and in the BALF cells of the female patients with SS in this study. The detection of male cells in the inflammatory lesions of the female patients but not in the peripheral blood suggests that maternal-fetal microchimerism has some role in the inflammation of SS. However, the number of subjects from whom both PBMC and LSG samples were available was small in this study. To test this hypothesis, a large number of subjects with both PBMC and LSG samples available will need to be examined.

One patient (No 47) did not have a male child or a history of abortion but tested positive for male DNA in both the peripheral blood and in the sample of LSG in this study. She had a history of blood transfusion five years before this study. Blood transfusion is another source of microchimerism. ${ }^{19}$ Therefore, it was likely that the male DNA seen in this patient was derived from the blood transfusion, although it was not possible to know the sex of the blood donor. Because male DNA was detectable not only in the inflammatory lesion but also in the peripheral blood in this particular case, it is difficult to know whether the microchimerism was related to her SS. Alternatively, it is possible that the amount of male cells that entered her blood circulation from blood products was very large and that these cells persisted for a long time. Unfortunately, we could not identify the extent of blood transfusion in this case.

It is still not clear how maternal-fetal microchimerism plays a part in the pathogenesis of autoimmune disease. ${ }^{2}$ It might be a direct effect of damage to host tissues by the non-host fetus derived immune cells, in a process analogous to that seen in CGVHD. ${ }^{21}$ One of the arguments against this hypothesis is the small number of non-host cells in the peripheral blood of patients with SSc, although it was suggested that the cells involved in the inflammatory reaction can be sequestered in the affected tissues. Indeed, it was suggested that the number of non-host male cells detected in the inflammatory lesions of SS was significantly more than that in the peripheral blood in this study, although their exact number was not measured. The characteristic histological feature of SS is the periductal lymphocytic infiltration in the salivary and lachrymal glands. Our previous studies showed that CGVHD after allogeneic bone marrow transplantation initially induces diffuse infiltration and, later, periductal infiltration of grafted T cells in salivary glands. ${ }^{12}{ }^{13}$ This observation suggests that the pathogenesis of inflammatory lesions of CGVHD and SS may have some differences between them and that the pathogenic cell does not belong to a single cell population. FISH in this study showed that the number of infiltrating non-host cells is much lower than that of host cells. Therefore, non-host cells might trigger and then establish inflammatory lesions in collaboration with host cells. Recently it was reported that male offspring $\mathrm{T}$ cells in women with SSc reacted with maternal 
major histocompatibility antigens and exhibited a Th2 oriented profile. ${ }^{22}$ Therefore, the study of the phenotypes or distribution of the non-host cells in the inflammatory lesions of SS might be essential to clarify how microchimerism plays a part in the pathogenesis of SS.

About $36 \%$ of female patients with SS tested positive for the Y chromosome-specific sequence in this study. This observation is only for the patients with male children; maternal-fetal microchimerism can occur between the mother and female children. The patients with SS examined might have had daughters, but we could not identify the cells derived from the female fetus in this study. Indeed, Artlett et al reported that cellular microchimerism of either male or female origin was detectable in $65 \%$ of patients with SSc by PCR analysis of HLA-Cw antigens. ${ }^{23}$ Moreover, it was also reported that chimeric cells of maternal origin can be found in the inflammatory lesions of juvenile idiopathic inflammatory myopathy and juvenile dermatomyositis. ${ }^{56}$ The incidence of microchimerism in patients with SS may be greater than that observed in this study as a future study may show.

In conclusion, maternal-fetal microchimerism was shown for the first time to exist in the salivary glands and affected the lungs of a significant number of female patients with SS in this study. The presence of non-host cells in the inflammatory lesions but not in the peripheral blood suggests a possible role for non-host cells in the pathogenesis of SS in the patients examined. Further studies are necessary to understand the precise mechanism of maternal-fetal microchimerism in contributing to the pathogenesis of SS.

\section{Authors' affiliations}

M Kuroki, A Okayama, T Sasaki, K Murai, H Tsubouchi, Department of Internal Medicine II, Miyazaki Medical College, Miyazaki, Japan R Shiba, Department of Oral and Maxillofacial Surgery, Miyazaki Medical College, Miyazaki, Japan

S Nakamura, Department of Oral and Maxillofacial Surgery, Graduate School of Dental Science, Kyushu University, Fukuoka, Japan

M Shinohara, Department of Oral and Maxillofacial Surgery, Kumamoto University School of Medicine, Kumamoto, Japan

\section{REFERENCES}

1 Bianchi DW, Zickwolf GK, Weil GJ, Sylvester S, DeMaria MA. Male fetal progenitor cells persist in maternal blood for as long as 27 years postpartum. Proc Natl Acad Sci USA 1996;93:705-8

2 Nelson JL, Furst DE, Maloney S, Gooley T, Evans PC, Smith A, et al. Microchimerism and HLA-compatible relationships of pregnancy in scleroderma. Lancet 1998;351:559-62.

3 Artlett CM, Smith JB, Jimenez SA. Identification of fetal DNA and cells in skin lesions from women with systemic sclerosis. N Engl J Med 1998;338:1186-91.
4 Aractingi S, Berkane N, Bertheau P, Goue CL, Dausset J Uzan S, et al Fetal DNA in skin of polymorphic eruptions of pregnancy. Lancet 1998;352:1898-901

5 Artlett CM, Ramos R, Jiminez SA, Patterson K, Miller FW, Rider LG, et al. Chimeric cells of maternal origin in juvenile idiopathic inflammatory myopathies. Lancet 2000;356:2155-6.

6 Reed AM, Picornell YJ, Harwood A, Kredich DW. Chimerism in children with juvenile dermatomyositis. Lancet 2000;356:2156-7.

7 Murata H, Nakauchi H, Sumida T. Microchimerism in Japanese women patients with systemic sclerosis. Lancet 1999;354:220.

8 Tanaka A, Lindor K, Ansari A, Gershwin ME. Fetal microchimerism in the mother: immunologic implications. Liver Transpl 2000;6:138-43.

9 Toda I, Kuwana M, Tsubota K, Kawakami Y. Lack of evidence for an increased microchimerism in the circulation of patients with Siögren's syndrome. Ann Rheum Dis $2001 ; 60: 248-53$.

10 Tzioufus AG, Moutsopoulos HM. Siögren's syndrome. In: Klippel JH, Dieppe PA, editors. Rheumatology. 2nd ed. London, UK: Mosby, 1998: 1-12.

11 Gratwhol AA, Moutsopoulos HM, Chused TM, Akizuki A, Wolf RO Sweet JB, et al. Sjögren's-type syndrome after allogenic bone-marrow transplantation. Ann Intern Med 1977;87:703-6.

12 Hiroki A, Nakamura S, Shinohara M, Oka M. Significance of oral examination in chronic graft-versus-host disease. J Oral Pathol Med 1994;23:209-15.

13 Hiroki A, Nakamura S, Shinohara M, Gondo H, Ohyama Y, Hayashi S, et al. A comparison of glandular involvement between chronic graft-versus-host disease and Siögren's syndrome. Int J Oral Maxillofac Surg 1996;25:298-307.

14 Honnma M, Tojo T, Akizuki M, Yamaguchi H. Criteria for Sjögren's syndrome in Japan. Scand J Rheumatol Suppl 1986;61:26-7.

15 Jager RJ, Anvret M, Hall K, Scherer G. A human XY female with a frame shift mutation in the candidate testis-determining gene SRY. Nature 1990;348:452-4.

16 Sinclair AH, Berta P, Palmer MS, Hawkins JR, Griffiths BL, Smith M, et al. A gene from the human sex-determining region encodes a protein with homology to a conserved DNA- binding motif. Nature 1990;346:240-4

17 Miyashita Y, Ono M, Ono M, Ueki H, Kurasawa K. Y chromosome microchimerism in rheumatic autoimmune disease. Ann Rheum Dis 2000:59:655-6.

18 Nakahori Y, Mitani K, Yamada M, Nakagome Y. A human Y-chromosome specific repeated DNA family (DYZ1) consists of a tandem array of pentanucleotides. Nucleic Acids Res 1986;14:7569-80.

19 McMilin K, Johnson RL. HLA homozygosity and the risk of related-donor transfusion- associated graft-versus-host disease. Transfus Med Rev 1993;7:37-4 1

20 Lee TH, Paglieroni T, Ohto H, Holland PV, Busch MP. Survival of donor leukocyte subpopulations in immunocompetent transfusion recipients: frequent long-term microchimerism in severe trauma patients. Blood 1999;93:3 127-39

21 Lawley TJ, Peck GL, Moutsopoulos HM, Gratwohl AA, Deisseroth AB. Scleroderma, Sïgren-like syndrome, and chronic graft-versus-host disease. Ann Intern Med 1977;87:707-9.

22 Scaletti C, Vultaggio A, Bonifacio S, Emmi L, Torricelli F, Maggi E, et al. Th2-oriented profile of male offspring T cells present in women with systemic sclerosis and reactive with maternal major histocompatibility complex antigens. Arthritis Rheum 2002;46:445-50.

23 Artlett CM, Cox LA, Jimenez SA. Detection of cellular microchimerism of male or female origin in systemic sclerosis patients by polymerase chain reaction analysis of HLA-Cw antigens. Arthritis Rheum 2000;43:1062-7. 